\title{
4D BIM for Construction Planning and Environmental Planning
}

\author{
Svetlana Sheina ${ }^{1, *}$, Ekaterina Seraya ${ }^{1}$, Viktor Krikunov ${ }^{1}$, and Nikita Saltykov ${ }^{1}$ \\ ${ }^{1}$ Don State Technical University, Sotsialisticheskaya. 162, 344022 Rostov-on-Don, Russia
}

\begin{abstract}
In order to develop an algorithm for selecting the most optimal organizational and technical solutions during design process, and the following automatization of this process, the problem of using 4D modeling programs in the organization and technology of construction is considered. A 4D -model cannot exist without detailed 3D-model and allows taking into account different variable factors in real time. In addition, software that uses 4D-modeling makes it possible to reduce significantly the time needed to prepare a project, to take into account flaws and mistakes at the different design stages. The concept of the 4D model connects in real time the elements of the model with the elements of the plan, which are recorded by means of programming. Algorithm proposed by us includes a control-system, when each subsequent stage implies the complete completion of the previous one. Unlike traditional design technology, when the object options may differ in the scope of work, preliminary cost, etc., the use of a simplified 4D model allows predetermining the best option. Also, BIM technology minimizes time costs by allowing designers and geodesic surveyors to work together. The information collected in the 4D model is saved by the operation company and is used during the operation of the object. The $4 \mathrm{D}$ programming allows us to optimize production processes, to visualize the construction of objects, and to solve the problems of the economic efficiency of the real estate objects construction with a high degree of probability.
\end{abstract}

\section{Introduction}

Innovative BIM technology is the construction of buildings and structures in the information space, high-quality control of operations carried out on all object life cycles. BIMtechnologies allow solving problems of a different spectrum: to visualize in details the internal and external appearance of the building, using images and to manage construction equipment in automatic mode.

BIM technologies make it possible to implement architectural concepts as close as possible to the capabilities of modern technologies and to predict in real time the probability of building construction with given characteristics while keeping the original architectural idea [2-5]. Before the advent of BIM technology, architectural design in the implementation of technological and organizational capabilities was based solely on experience and exper-

\footnotetext{
* Corresponding author: rgsu-gsh@mail.ru
} 
iment. At present, the construction of prognostic models is possible based on computer multifunctional and multi-level modeling of architectural and construction reality.

Nowadays, in the world, the actual problem of design and arrangement of construction is the consideration of variable factors in real time. BIM-technologies allow making this account with the help of modern innovative methods of 4D-modeling.

The 4D-modeling method developed in the early 2000s, on the one hand, turned out to be in demand, and on the other hand, is too complicated for the widespread implementation.

The authors of the article propose a simplified 4D-modeling system using BIMtechnology in the organization of construction.

\section{Materials and Methods}

BIM-modeling for the following operation of the building goes beyond the threedimensional spatial model and uses 4.5, sometimes 6 measurements. Each level (measurement) allows for the accumulation of more and more information. Each level corresponds to the level of presentation of information. Thus, the developed 3D information model is the basis for the 4-, 5-, 6D-models and is the starting point for development of working documentation, for design and manufacturing of building structures, for creation of specifications, for the economic assessment and arrangement of the building construction (Fig.1).

3D BIM is an integrated data model from which various stakeholders, such as architects, design engineers, builders and project owners, can extract and contribute an information according to their needs. The 3D BIM visualization capabilities allow participants to not only see the building in three dimensions, but also automatically update these views during the project life cycle. The 3D BIM helps participants to manage more effectively their interdisciplinary collaboration in modeling and analysis of the complex problems.

4D BIM is an approach in design, when an object is considered not only in space, but also in time. It is used for activities related to site planning. The fourth dimension of BIM allows participants to extract and visualize the course of their activities throughout the project's life cycle. Usage of 4D BIM technology can bring to the improvement of control over the conflicts detection or the complexity of changes occurring during the construction.

5D BIM is an information model that also includes the cost of the project. It is used for budget tracking and analysis of the expenses. The fifth dimension of BIM, associated with 3D and 4D (time), allows participants to visualize the course of their activities and the costs associated with it over time. The use of 5D BIM technology can bring to more accuracy and predictability of project estimates, changes in volume and materials, equipment or labor.

6D BIM is an information model that allows you to effectively operate the building, including security monitoring, current and planned repair, and reconstruction. Sixdimensional information modeling of buildings helps to analyze the energy consumption. The use of 6D BIM technology can bring to more complete and accurate energy estimates in the early stages of the design process.
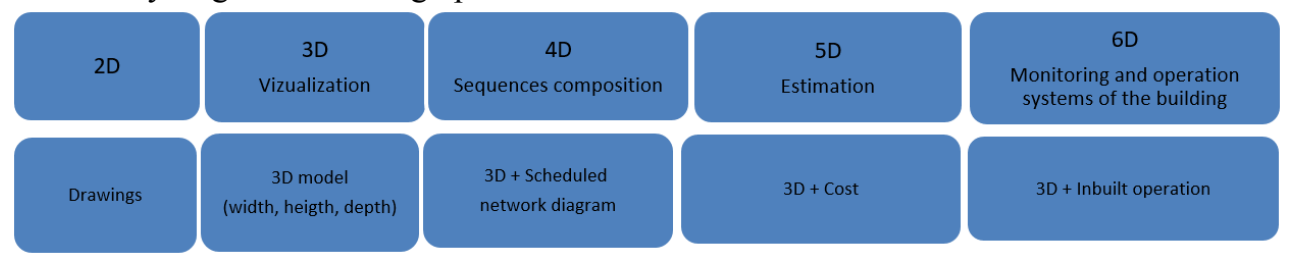

Fig. 1. BIM dimensions

As a specific case of BIM-modeling - 4D-modeling allows you to break the construction process into a number of structural categories controlled in real time and space. 
The nominal 4D-modeling system includes the actual 3D model of the object and the network model (scheduled network diagram) of its construction. The three-dimensional model transfers the basic information of the object into an intuitively understandable form, and the network model shows the technological and time component of the work done [1]. The calculation of resources, which allows you to select the main building technologies, economically rational organization of work, is an obligatory part of the creation of 4Dmodel. Modern information technologies make it possible to automate the calculations and application of solutions, the installation of main and auxiliary equipment on the site. When selecting the most rational location of the crane, temporary roads, storage sites, it becomes possible to move equipment between objects during the construction of complexes.

Visualization of the distribution of resources in the information model, as well as cost and material and technical indicators allows accelerating the planning and organization of object or complex of objects construction. The system offered by us allows us to take into account flaws and mistakes at the stages of construction management in all specific areas (Fig.2).

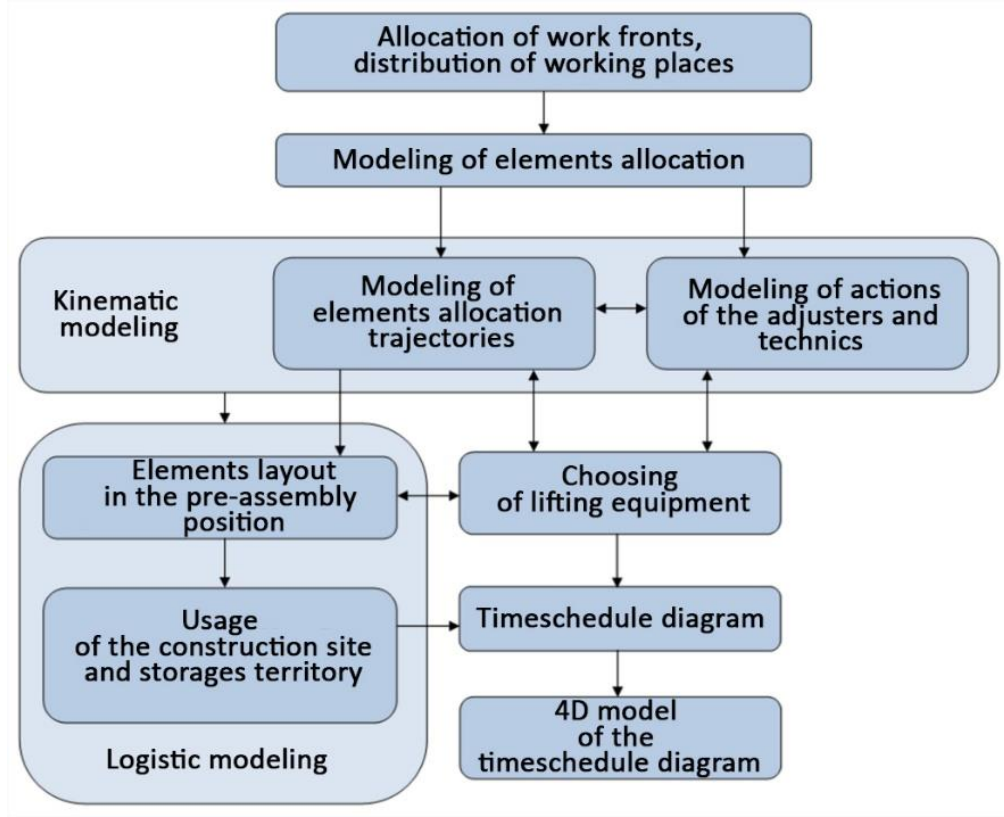




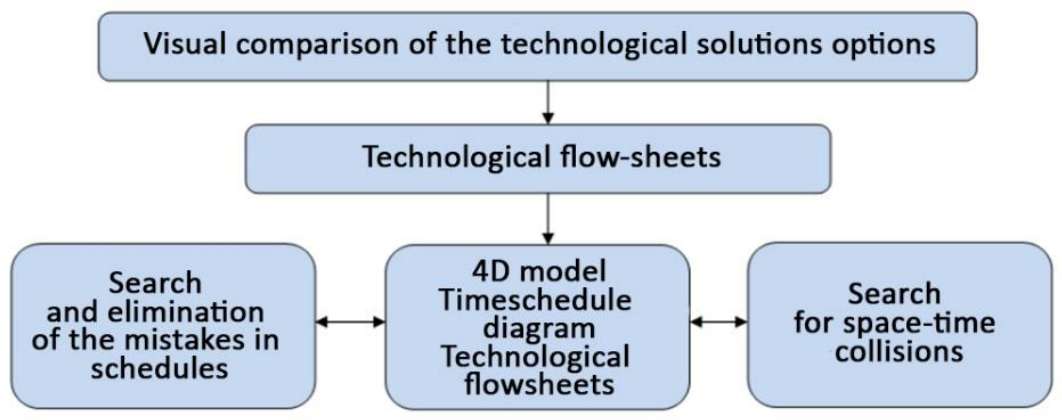

Fig. 2. Optimal organizational and technological solutions

As a result, control of the content of plans and projects as a whole becomes much simpler, since the analysis of the model at the same time highlights missing elements or unrealized links. The process of automatic search for optimal solutions, by using rationally resources and technics, optimizes the object construction process. Software using 4Dmodeling makes it possible to significantly reduce the time for project preparation [3-5].

\section{Results}

We consider the situation when the graphic 4D model significantly simplifies the visual comparison. The second task is to compare visually the plan with the fact or options of organizational and technological solutions. This is especially true for the construction of facilities network when works are being performed in parallel on several sites, which leads to significant differences with the construction plan of facilities. It is impossible to develop a realistic approach to the objects construction without proper visualization of the process, which is much simpler with 4D simulation programs [6].

For example, let us consider the load associated with entering the site. It often happens when a large equipment unit in conditions of high density of construction limits the traffic of trucks with materials and other equipment, which leads to delays in the construction process. 4D modeling also allows you to adjust and optimize this process.

The process of creating a 4D model is simplified by creating a detailed 3D model comparable to a detailed work plan. Individual elements (or groups) of 3D-models are associated with combinatorial tasks and deadlines. It can be computational, preparatory or installation works, depending on the characteristics of the combinatorial problem. The proposed concept of 4D model links the elements of the model with the elements of the plan in real time, which are recorded by means of programming.

The algorithm proposed by us (Fig.2) that includes a control-system, when each subsequent stage assumes the complete completion of the previous one. The following technology of using the information model is also proposed: to save the information model in the electronic technical passport of the object, tied to the electronic map of the city, built in the ArcGIS environment.

With the tools of currently popular software systems, such as MS Project + Autodesk, JI Orbiter, IndorCAD, it is possible to envisage such scenarios in which the introduction of this algorithm becomes mandatory and the monitoring of the maintenance of the planned work is automated at all stages of the plan.

Thus, problem solution is being automated, which is facilitated by preliminary prepared options of the implementation paths selection, for example, all of the same transport access to the site, taking into consideration spatial interferences. Until this signal factor will not be passed through in the algorithm, the transition to the next level of project development is 
impossible, and the high visualization and self-learning software allows you to quickly select the optimal scheme for solving the problem using the analogy method.

Therefore, when creating a model, it is always important to imagine what the result should be and how to achieve it.

For the convenience of work with the program, the developers made sure that it was possible to combine the objects of the $3 \mathrm{D}$ model directly in the program, eventually working with a specific type of work or splitting the element into stages becomes easier, since there is no need to rearrange the model according with the schedule.

4D model is visualized both completely and in parts. A complete visualization is a project as a whole, and parts represent different stages of the design. Thus, user can see the events he needs at any time interval, including changes made on different stages.

Visualization of the construction process in real time allows all project participants to see both the complete picture and various details. This helps to perceive the process better and reduces the number of errors that might be made both in the design and in construction of the objects directly.

The technological algorithm for simplifying 4D modeling assumes:

- Preparation of the composition of the calculation tools, including the schedule calculation, calendars, possibility of splitting the elements of the model into the construction staging, etc.;

- Verification within the general 4Dmodel of 3D elements and fragments of scheduled network diagram, integration with the most advanced for today Microsoft Project system;

- Usage of the system does not consider a long process of applying and rejection of other systems. In most cases, it simply complements existing CAD and project management systems.

- Complementation of existing CAD by the developed algorithm.

In practice, this means the use of 4D-modeling in conjunction with traditional technologies that provide additional control.

\section{Discussion}

The proposed technology has been implemented as follows.

Instead of the traditional development of several object-planning options, one is chosen, with pre-calculated characteristics, which is facilitated by the automated processing of the proposed model based on the entered data. If, as a result of designing by a traditional method, the options of an object may differ in the amount of work, preliminary cost, etc., then using a simplified 4D model allows you to pre-determine the optimal option.

At the design stage, the results of engineering surveys are automatically transformed into a digital terrain model, which immediately assumes the choice of the optimal building scheme, foundation structures, calculation of the scope of work, etc. depending on the intended object of construction.

The traditional approach to design implies that the development of the project begins only after the completion of the digital terrain model (DTM), which inevitably entails considerable time costs. BIM technology minimizes time costs by doing the job of specifying the DTM and actual design independently.

Parallel work of designers and topographic surveyors is possible using a common data environment (COD), which provides a terrain model prepared separately as a DTM layer. When filling out a digital model with information about buildings, engineering communications and other significant objects, design engineers using SOD obtain changes in the model and can adjust design decisions based on these changes. This allows you to notice conflicts 
in the early stages of the design process and make appropriate changes in the design solution long before construction will start.

Designed objects of the model are fully parameterized: in the design process, all parameters of the object can be changed without additional calculations.

Using a common data environment allows all the process participants not only to see the actual information about the designed object, but also makes it possible to comment on individual project objects at different stages. In turn, designers can see these comments directly during the design and immediately make the necessary changes to the model.

Designed objects of the model are fully parameterized: in the design process, all parameters of the object can be changed without additional calculations.

Usage of the common data environment allows all participants in the process not only to see the actual information about the designed object, but also makes it possible to comment on individual project objects at different stages. In their turn, designers can see these comments directly during the design and immediately make the necessary changes to the model.

After construction is completed, the stage of building operation begins. At this stage information models controlled by object information systems are created in common. The 4D model created earlier can be used during the operation of the object. Content of the data needed to eliminate problems at different stages of life cycle has different requirements.

As soon as the operational phase begins, all 4D model data that can be used at this stage is transferred to the database of the operating company. The project itself is also located in a shared data storage. At the same time, connection of the various elements of the project and their corresponding objects in the database is not lost. The company continue to supplement the data with certification, diagnostic and other information materials for all buildings and structures.

During the process of reconstruction or other work bringing changes to the object, all information about the updated characteristics, new documentation and other new data are entered into the 4D model.

The basis for the need for repair or reconstruction works is the data on the results of diagnostics, which are saved by the operating company in the relevant sections of the 4D model. These data become initial when performing repairs in the CAD system. Also, in addition to the information already accumulated at the operation stage, the data created at the design stage are used. Thus, in order to develop a repair or reconstruction project, the operating company must ensure the transfer of the accumulated data to the design and construction organization.

4D-modeling practically excludes all types of collisions, even complex ones, for specialists and space-time specialists, thanks to the rendering of dynamic visualization and automatic detection of intersections.

\section{Conclusions}

The key benefits of BIM technology are a significant reduction in human factors to ensure high quality, avoiding errors and improving the accuracy of results, as well as reduction of time and labor costs.

Thus, objects modeled and built using BIM-technologies have much more efficiency. This is proved by the fact that the complex model is guaranteed to ensure transparent and productive construction and operation of the property object [4, p. 334]. Effective design and operation allows for a high degree of financial transparency at all stages of the object construction. Contractor is protected from unreasonable costs and unverified losses.

Thus, 4D programming makes it possible to optimize production processes, to visualize construction of objects, and to solve problems of the economic efficiency of the real estate construction with a high degree of probability. 


\section{References}

1. O. Gaybarian, G. Myasishchev, The practical application of client-oriented technologies of linguistic communication. Engineering journal of don 4(47), p.193 (2017).

2. G. Goddess, The Model of Linguistic persona and Its Relation to Different Types of Texts, p. 144. Moscow (2010).

3. E. Shirina, O. Gaybarian, G. Myasischev, Effective management of construction company in terms of linguistic communication IOP Conf. Series: Earth and Environmental Science 90 (2017) 012077.

4. M. Bloch, Pragmatism, Ethics and Aesthetics of Communication. Linguistics and language education in modern Russia, pp. 43-67. Moscow (2004).

5. I. Sokolov, PhD Thesis abstract, p. 28. Moscow (2007).

6. V. Kostyuchenko, The System Organization and Management of Construction Rostov/Don, p. 115 (2007).

7. O. Kliuchnikova, O. Pobegaylov, Procedia Engineering 150, pp. 2168 - 2172 (2016).

8. D. Hussey, Strategic Management, p. 384. Moscow (2007).

9. O. Pobegaylov, G. Myasishchev, O. Gaybarian, Procedia Engineering 150, pp. 21732177 (2016).

10. K. Abulkhanova, Russian mentality: cross-cultural and typological approaches. Russian mentality: issues of psychological theory and practice, p. 37. Moscow: Institute of psychology RAS (1997).

11. A. Babanov, The dynamics of the development of sustainable investment climate in regions with unstable economies, p. 374. Moscow: ITKOR (2011).

12. A. Babanov, Cyclic backwardness in infrastructure investment in the regions Economic and Legal. Magazine "Business-in-law", p.3. Moscow, Media - WAC (2011).

13. I. Blank, Fundamentals of Financial Management, p. 226. Kiev, Nika-Tsentr (2008).

14. P. Richard, Underhile Ric, A. Wall., Keeling Liberal Education 93(4), pp. 22-31 (2007).

15. G. Grice, Linguistic pragmatics Vol. XVI, pp. 217-237 (2009).

16. V. Kolesov, Language and mentality, p. 357. Saint-Petersburg: Petersburg Oriental Studies (2004).

17. T. Kolmykova, Investment analysis, p. 204. Moscow, INFRA-M (2009).

18. A. Shmelev, Russian language model of the world: materials for the dictionary, p. 178. Moscow: Languages of Slavonic culture (2007).

19. A. Leont'ev, Psychophysiological mechanisms of speech. General linguistics: forms of existence, function, language history, pp. 314-375. Moscow (2012).

20. T. Vladimirova, Called into the fellowship: the Russian discourse in the intercultural communication 56, p. 13. Moscow: Book house "LIBROKOM" (2010). 